\title{
Postobturation Pain in Asymptomatic Non Vital Single Rooted Maxillary Teeth Following Single and Two Visit Root Canal Treatment
}

\author{
Salma Jabeen ${ }^{1 *}$ \\ Khurshiduzzaman ${ }^{2}$
}

'Department of Conservative Dentistry and Endodonties, Dhaka Dental College

Mirpur -14, Dhaka, Bangladesh.

${ }^{2}$ Department of Dentistry Dinajpur Medical College Dinajpur, Bangladesh.
*Correspondence to:

\section{Dr. Salma Jabeen}

Assistant Professor

Department of Conservative Dentistry and Endodonties Dhaka Dental College, Mirpur-14, Dhaka, Bangladesh. Mobile : +88 01716842505

Email :drsj17@gmail.com

www.banglajol.info/index.php/CMOSHMCJ

\begin{abstract}
Objectives : The purpose of the present study was to asses the incidence and severity of pain after single and two visit Root Canal Treatment ( RCT ) / endodontic treatment in asymptomatic non vital single rooted maxillary teeth. Methods : Eighty one cases of endodontically involved asymptomatic, non vital, single rooted maxillary teeth without evidence of periapical radiolucency in radiograph were selected for this study. The patient were divided into two treatment group. In single visit group, all teeth were prepared and filled using the standardized preparation and lateral condensation filling technique. In the two visit treatment group, at the first appointment, the teeth were prepared and dressed with calcium hydroxide paste for 7 days. At the second appointment, the teeth were prepared and obturated by using lateral condensation technique. The frequency of post obturation pain was recorded as no pain, slight/ mild, moderate and severe pain and evaluated at the day 1 and at the day 7 after obturation. The data were analyzed statistically by using SPSS version 16. p-value $<0.05$ was taken as significant. Results : No significant difference in post obtuation pain was found in between single and two visit RCT in maxillary teeth. At the day 1 and 7 after obturation, single visit $(n=41)$ group and two visit $(n=40)$ group similarly experienced moderate pain $(2.5 \%$ and $1.1 \%$ respectively in both group). At day 1 and 7 after obturation, mild pain is more in single visit than two visit group. However, there was no statistically significant difference in pain between the two groups. No one experienced severe pain in two groups. Conclusion: The incidence and severity of post obturation pain did not differ between single and two visit RCT in asymptomatic non vital single rooted maxillary teeth.
\end{abstract}

Key words: Post obturation pain; Root canal treatment; Single visit; Two visit; Maxillary teeth.

\section{INTRODUCTION}

A major goal of Root Canal Treatment ( RCT) / endodontic treatment is the preservation of natural teeth. But RCT or endodontic treatment can be followed by short and long term complications ${ }^{1}$. Some of the problems of RCT are post obturation pain, interappointment pain and swelling ${ }^{2}$. The development of postobturation pain after RCT is a poor indicator of pathosis and unreliable predictor of long term success ${ }^{3}$. Completion of RCT can be done by single visit or multivisit procedures. The concept of doing complete endodontic treatment in one visit is not new. It was there from at least 100 years ${ }^{4}$. The completion of endodontic treatment in a single appointment has been currently used. Although the argument for single visit treatment depends on the convenience, patient acceptance, and reduced post operative pain ${ }^{5}$. Multiple visit RCT has long been taught to undergraduate dental students and is regarded as a safer procedure than single visit RCT ${ }^{3,6}$. Existing literatures on single as compared to multiple visit endodontic treatment gives conflicting opinions and recommendations ${ }^{7}$. 
There are several studies on single and multivisit root canal treatment and its out come. A few studies on asymptomatic non vital teeth ${ }^{8,9,10}$. But there is a very few literatures on post obturation pain in asymptomatic, non vital, single rooted maxillary teeth following RCT.

Therefore, the aim of this clinical study was to asses the incidence and severity of pain after one and two visit RCT/ endodontic treatment in asymptomatic, non vital, single rooted maxillary teeth.

\section{MATERIALS AND METHODS}

A total of 81 cases of endodontically involved asymptomatic, non vital, single rooted maxillary teeth without any evidence of periapical radiolucency in periapical radiograph, were selected for this study. The study was conducted in Department of Conservative Dentistry and Endodontics, Dhaka Dental College and Hospital, Dhaka, Bangladesh .The sample size was divided into two treatment group.

Group I : Single visit treatment group $(n=41)$

Group II : Two visit treatment group $(\mathrm{n}=40)$

Diagnosis of non vital asymptomatic tooth was confirmed by pulp sensitivity test applying heat and cold method and examination of pre- operative periapical radiograph was done to exclude periapical lesion cases. The canal of all teeth were prepared and filled using the standardized preparation and lateral condensation filling technique. In the single visit treatment group, at the first appointment, the teeth were isolated, biomechanically prepared, dried and obturated with Gutta- Percha points and zinc oxide eugenol sealer using lateral condensation technique. Where as in the two visit treatment group, at the first appointment, the teeth were isolated, biomechanically prepared, dried, dressed with calcium hydroxide paste and sealed. At the second appointment, seven days after first one, the teeth were isolated, irrigated, dried and obturated with Gutta- Percha points and zinc oxide eugenol sealer using lateral condensation technique.

The patient was asked to report, record or interviewed any pain experience at the day 1 and 7 after obturation. The presence or absence of pain or the appropriate degree of pain was recorded and graded as :-

1. No Pain (Grade 0) :- The treated tooth feels normal.

2. Slight / Mild Pain (Grade I) :- Any discomfort, no matter how many brief in duration that do not require medication.

3. Moderate Pain (Grade II) :- Pain tolerable or is tolerable by analgesics.

4. Severe Pain (Grade III) :- Pain not responding to analgesics, disturb normal activity/ sleep/ impairment of masticatory function.

The data was analyzed by a computer based software programStatistical Package for Social Science (SPSS version- 16). p- value $<0.05$ considered as significant.

\section{RESULTS}

The study included 81 patients. They were divided into two treatment groups. Single visit treatment group was assigned as Group I $(n=41)$ and two visits treatment group was assigned as Group II $(n=40)$. We intended to compare the outcome of post obturation pain in asymptomatic non vital single rooted maxillary teeth at day one and at day seven between single visit treatment group and two visit treatment group.

Table 1 : Comparison of age and gender between single and two visit groups ( $\mathrm{n}=81$ ).

\begin{tabular}{llcrll}
$\begin{array}{l}\text { Age and gender } \\
\text { of the patients }\end{array}$ & $\begin{array}{c}\text { Group-I } \\
(\mathrm{n}=41)\end{array}$ & \multicolumn{1}{c}{$\begin{array}{c}\text { Group-II } \\
(\mathrm{n}=40)\end{array}$} & $\begin{array}{l}\text { Total } \\
(\mathrm{n}=81)\end{array}$ & P value \\
Gender & Male & $26(32.1 \%)$ & $19(23.5 \%)$ & $45(55.6 \%)$ & $0.150^{\mathrm{NS}}$ \\
& Female & $15(18.5 \%)$ & $21(25.9 \%)$ & $36(44.4 \%)$ & \\
\multirow{2}{*}{ Age group } & $>25$ years & $14(17.3 \%)$ & $9(11.1 \%)$ & $23(28.4 \%)$ & $0.245^{\mathrm{NS}}$ \\
& $<25$ years & $27(33.3 \%)$ & $31(38.3 \%)$ & $58(71.6 \%)$ & \\
\multirow{2}{*}{ Age in years } & Mean \pm SD & $23.68 \pm 6.64$ & $21.83 \pm 6.04$ & $22.77 \pm 6.38$ & $0.192^{\mathrm{NS}}$ \\
\hline
\end{tabular}

Group I: Single visit treatment group

Group II: Two visits treatment group

$\mathrm{NS}=$ Not significant

$\mathrm{p}$ value derived from Pearson Chi-Square test/ Student t-test

There were 45 (55.6\%) male and 36 (44.4\%) female. Among the Group I patients, 26(32.1\%) were male and 15(18.5\%) were female and among the Group II patients, 19(23.5\%) were male and $21(25.9 \%)$ were female. The difference in gender between two groups were not significant $(\mathrm{p}=0.150)$ (Table 1).

The age of the total patients ranged from 15-40 years (mean age $22.77 \pm 6.38$ years). The mean \pm SD age of Group I was $23.68 \pm 6.64$ years and of Group- II was $21.83 \pm 6.04$ years. There was no significant difference in age between two groups $(p=0.192)$ (Table 1). Fourteen (17.3\%) patients in Group I and 9(11.1\%) patients in Group II belonged to age $>25$ years and $27(33.3 \%)$ patients in Group I and 31(38.3\%) Patients in Group II belonged to age $<25$ years. However, the difference in age group between two groups was not significant $(\mathrm{p}=0.245)$ (Table 1).

Table 2 : Comparison of baseline characteristics between single and two visit groups $(\mathrm{n}=81)$.

\begin{tabular}{|c|c|c|c|c|c|}
\hline $\begin{array}{l}\text { Baseline } \\
\text { Characterist }\end{array}$ & & Group I & $\begin{array}{l}\text { Group II } \\
(\mathrm{n}=41)\end{array}$ & $\begin{array}{l}\text { Total } \\
(n=40)\end{array}$ & $\begin{array}{l}\text { P value } \\
(n=81)\end{array}$ \\
\hline Occupation & $\begin{array}{l}\text { Business } \\
\text { House wife } \\
\text { Service } \\
\text { Student }\end{array}$ & $\begin{array}{r}2(2.5 \%) \\
6(7.4 \%) \\
5(6.2 \%) \\
28(34.6 \%)\end{array}$ & $\begin{array}{r}3(3.7 \%) \\
3(3.7 \%) \\
10(12.3 \%) \\
24(29.6 \%)\end{array}$ & $\begin{array}{r}5(6.2 \%) \\
9(11.1 \%) \\
15(18.5 \%) \\
52(64.2 \%)\end{array}$ & $0.367^{\mathrm{NS}}$ \\
\hline Tooth type & $\begin{array}{l}\text { 2nd premolar } \\
\text { Canine } \\
\text { Central incisor } \\
\text { Lateral incisor }\end{array}$ & $\begin{array}{r}5(6.2 \%) \\
7(8.6 \%) \\
21(25.9 \%) \\
8(9.9 \%)\end{array}$ & $\begin{array}{r}13(16.0 \%) \\
5(6.2 \%) \\
18(22.2 \%) \\
4(4.9 \%)\end{array}$ & $\begin{array}{l}18(22.2 \%) \\
12(14.8 \%) \\
39(48.1 \%) \\
12(14.8 \%)\end{array}$ & $0.142^{\mathrm{NS}}$ \\
\hline Side & $\begin{array}{l}\text { Left } \\
\text { Right }\end{array}$ & $\begin{array}{l}20(24.7 \%) \\
21(25.9 \%)\end{array}$ & $\begin{array}{l}19(23.5 \%) \\
21(25.9 \%)\end{array}$ & $\begin{array}{l}39(48.1 \%) \\
42(51.9 \%)\end{array}$ & $0.908^{\mathrm{NS}}$ \\
\hline History & $\begin{array}{l}\text { Filling } \\
\text { Trauma }\end{array}$ & $\begin{array}{l}16(19.8 \%) \\
25(30.9 \%)\end{array}$ & $\begin{array}{l}20(24.7 \%) \\
20(24.7 \%)\end{array}$ & $\begin{array}{l}36(44.4 \%) \\
45(55.6 \%)\end{array}$ & $0.320^{\mathrm{NS}}$ \\
\hline Sign & $\begin{array}{l}\text { Carries } \\
\text { Discoloration }\end{array}$ & $\begin{array}{l}16(19.8 \%) \\
25(30.9 \%)\end{array}$ & $\begin{array}{l}20(24.7 \%) \\
20(24.7 \%)\end{array}$ & $\begin{array}{l}36(44.4 \%) \\
45(55.6 \%)\end{array}$ & $0.320^{\mathrm{NS}}$ \\
\hline $\begin{array}{l}\text { Periodontal } \\
\text { condition }\end{array}$ & $\begin{array}{l}\text { Average } \\
\text { Good } \\
\text { Poor }\end{array}$ & $\begin{array}{r}41(50.6 \%) \\
0(0.0 \%) \\
0(0.0 \%)\end{array}$ & $\begin{array}{r}35(43.2 \%) \\
1(1.2 \%) \\
4(4.9 \%)\end{array}$ & $\begin{array}{r}76(93.8 \%) \\
1(1.2 \%) \\
4(4.9 \%)\end{array}$ & $0.065^{\mathrm{NS}}$ \\
\hline
\end{tabular}

Group I : Single visit treatment group. Group II : Two visits treatment group.

Ns= Not significant. p value derived from Pearson Chi-Square test. 
By occupation, most of the patients were student $(n=52$, $64.2 \%)$ followed by service holder $(\mathrm{n}=15,18.5 \%)$ and house wife $(n=9,11.1 \%)$. The occupation of the participant of the two groups was similar with no significant difference $(\mathrm{p}=0.367)$ as shown in table 2 .

Mostly affected teeth were central incisor $(25.9 \%$ in Group I and $22.2 \%$ in Group II). Other affected teeth were $2^{\text {nd }}$ premolar, canine and lateral incisor. No significant difference was observed in tooth type between groups ( $\mathrm{p}=0.142$ ) (Table 2).

Thirty-nine (48.1\%) teeth belonged to left side of the maxillary arch and rest $42(51.9 \%)$ belonged to right side of the maxilla. Side of the teeth studied did not differ significantly $(\mathrm{p}=0.908)$ between Group I (left vs right, $24.7 \%$ vs $25.9 \%$ ) and Group II (left vs right, $23.5 \%$ vs $25.9 \%$ ) (Table 2 ).

History revealed that $36(44.4 \%)$ patients had previous treatment with filling and $45(55.6 \%)$ had trauma. Filling as clinical history was slightly more in Group II than Group I $(24.7 \%$ vs $19.8 \%)$, and trauma was slightly more in Group I than Group II $(30.9 \%$ vs $24.7 \%)$ but the difference was not significant $(\mathrm{p}=0.320)$ (Table 2$)$.

Clinically, 36(44.4\%) patients had dental carries and 45(55.6\%) had discoloration of tooth. The sign of dental carries was more in Group II than Group I (24.7\% vs $19.8 \%)$ and sign of discoloration was more in Group I than Group II (30.9\% vs $24.7 \%$ ) but the difference was not statistically significant $(\mathrm{p}=0.320)$ (Table 2).

The peri odontal condition was average in $76(93.8 \%)$ patients, good in $1(1.2 \%)$ patients and poor in $4(4.9 \%)$. All 41(50.6\%) patients of Group I and 35(43.2\%) of Group II had average periodontal condition. Among the patients of Group II, 4(4.9\%) had poor and $1(1.2 \%)$ had good periodontal condition, however the difference between groups was not significant $(\mathrm{p}=0.065)$ (Table 2).

Table 3 : Comparison of degree/severity of pain between single and two visit groups $(\mathrm{n}=81)$.

\begin{tabular}{llrlrl}
$\begin{array}{l}\text { The day after } \\
\text { Postobturation }\end{array}$ & $\begin{array}{l}\text { Degree/severity } \\
\text { of pain }\end{array}$ & $\begin{array}{l}\text { Group I } \\
(\mathrm{n}=41)\end{array}$ & $\begin{array}{l}\text { Group II } \\
(\mathrm{n}=40)\end{array}$ & $\begin{array}{l}\text { Total } \\
(\mathrm{n}=81)\end{array}$ & P value \\
$\begin{array}{l}\text { At the day } 1 \text { after } \\
\text { Postobturation }\end{array}$ & $\begin{array}{l}\text { Moderate pain } \\
\text { Mild pain }\end{array}$ & $\begin{array}{r}2(2.5 \%) \\
6(7.4 \%)\end{array}$ & $\begin{array}{r}2(2.5 \%) \\
2(2.5 \%)\end{array}$ & $\begin{array}{r}4(4.9 \%) \\
8(9.9 \%)\end{array}$ & 0.347 NS \\
& No pain & $33(40.7 \%)$ & $36(44.4 \%)$ & $69(85.2 \%)$ & \\
$\begin{array}{l}\text { At the day 7 after } \\
\text { Postobturation }\end{array}$ & $\begin{array}{lllll}\text { Moderate pain } \\
\end{array}$ & $1(1.1 \%)$ & $1(1.1 \%)$ & $2(2.5 \%)$ & $0.368 \mathrm{NS}$ \\
& Mild pain & $2(2.5 \%)$ & $0(0.0 \%)$ & $2(2.5 \%)$ & \\
& No pain & $38(46.9 \%)$ & $39(48.1 \%)$ & $77(95.1 \%)$ & \\
\hline
\end{tabular}

Group I : Single visit treatment group.

Group II : Two visits treatment group.

NS= Not significant.

$\mathrm{p}$ value derived from Pearson Chi-Square test.
Out of 81 patients, mild and moderate pain was experienced by $8(9.9 \%)$ and $4(4.9 \%)$ patients respectively and $69(85.2 \%)$ patients experienced no pain at the day 1 after postobturation. Whereas, mild and moderate pain was experienced by $2(2.5 \%)$ patients each and 77 (95.1\%) patients experienced no pain at the day 7 after postobturation. None experienced severe pain in both follow-up days (Table 3).

At the day 1 after postobturation both the groups similarly experienced moderate ( $2.5 \%$ in both) pain. Group I experienced mild pain more than Group II (7.4\% vs $2.5 \%$ ). Group II had more patients than Group I who experienced no pain (44.4\% vs $40.7 \%)$. However, there was no statistically significant difference between Group I and II in experiencing severity of pain $(\mathrm{p}=0.347)$ (Table 3$)$.

At the day 7 after postobturation both the groups similarly experienced moderate (1.1\% in both) pain. Group I experienced mild pain more than Group II (2.5\% vs $0.0 \%)$. Group II had more patients than Group I who experienced no pain $(48.1 \%$ vs $46.9 \%)$. However, there was statistically no significant difference between Group I and II in experiencing severity of pain $(\mathrm{p}=0.368)$ (Table 3$)$.

\section{DISCUSSION}

The result of this clinical study did not show a significant difference in post obturation pain in asymptomatic, non vital, single rooted maxillary teeth, following single and two visit RCT.

Outcome of post obturation pain and flare up following single visit and multivisit RCT is a long term debate. Several researchers studied on this regards with conflicting results. Oginni and Udoye, Soltanoff and Montclair, Ether, Ng Y-I et al and Gesi et al concluded more pain in single visit than multivisit $\mathrm{RCT}^{3,11-14}$. On the contrary, Albashaireh and $\mathrm{Al}$ negrish and Roane et al showed more pain in multivisit than single visit $\mathrm{RCT}^{6,7}$.

Al negrish and Habahbeh and Walton and Fouad observed no significant differences between one and two visits RCT and our study also support them ${ }^{9,15}$.

Though, we studied only maxillary arch teeth, Dall et al and Alcam and Tinaz found more pain in mandibular arch than maxillary arch. Where are Imura and Zuolo, Ince et al and Eleazer and Eleazer found no significant differences in pain between maxillary and mandibular teeth ${ }^{16-20}$.

We studied maxillary single rooted teeth i.e 2nd premolar, canine, central incisor and lateral incisor teeth with no significant difference in incidence and severity of pain in single and two visit RCT. There is also no difference in observation of pain at day 1 and day 7 after postobturation. Mulhern et al treated maxillary single rooted, symptom less, necrotic teeth in one and two visit RCT, reported no significant difference in post obturation pain in between two group ${ }^{8}$. Fava studied sixty maxillary central incisor with asymptomatic necrotic pulp in one and two visits ${ }^{21}$. There is no difference was observed in the incidence of post operative pain between the two group. 
Clem found that maxillary anterior teeth and premolars were involved with significantly less increased post treatment pain than other teeth ${ }^{22}$. Our study is consistent with them.

There are several studies on post obturation pain. These studies have variations in study design, severity of pain assessment, pre operative condition of teeth, post operative follow up, technique of RCT, analysis of data etc, resulting variation in studies of post obturation pain and giving different opinions and recommendations.

\section{CONCLUSION}

Though multivisit RCT may considered as safer, under the condition of our study, it is found that there is no significant difference of post obturation pain in single visit and two visit RCT in single rooted maxillary asymptomatic non vital teeth.

\section{DISCLOSURE}

All the authors declared no competing interest.

\section{REFERENCES}

1. Glenon J P, Ng Y-L, Setchell D J, Gulabirvala K. Prevalence and factors affecting postpreparation pain in patients undergoing two- visit root canal treatment. Int Endo J. 2004; 37:29-37.

2. Oginni A O, Udoye CI . Endodontic flare ups: Comparison of incidence between single and multiple visit procedures in patients attending a Nigerian teaching hospital. BMC Oral Health. 2004;4(1):4.

3. DiRenzo A, Gresla T, Johnson BR, Rogers M, Tucker D, BeGole EA. Postoperative pain after 1 and 2 visit root canal therapy . Oral Surg Oral Med Oral Pathol Oral Radiol Endod 2002; 93: 605-610.

4. Nandakishore KJ, Shija AS , Vinaychandra R. Single visit endodontics : A review . Journal of health sciences and research. 2011; 2(1).

5. Inamoto K, kojima K, Nagamatsu K, Hamaguchi A, Nakata K, Nakamura H . A survey of the incidence of single visit endodontics . J Endod. 2002; 28:371-374.

6. Albashaireh Z S M, Alnegrish A S. Postobturation pain after single and multiple visit endodontic therapy. A prospective study. J Dent.1998;26:227-232.

7. Roane J B, Dryden J. A, Grimes E W. Incidence of post obturation pain after single and multiple visit endodontic procedures . Oral Surg Oral Med and Oral Pathol. 1983;55(1):68-72.

8. Mulhern JM, Patterson SS, Newton CW, Ringel AM. Incidence of postoperative pain after one appointment endodontic treatment of asymptomatic pulpal necrosis in single rooted teeth . J Endod. 1982;8(8):370-375.

9. Al- Negrish A R S, Habahbeh R. Flare up rate related to root canal treatment of asymptomatic pulpally necrotic central incisor teeth in patients attending a military hospital. J Dent. 2006;34:635-640.

10. Jabeen S, Khursiduzzaman . Incidence of post obturation pain following single and multi visit root canal treatment in a teaching hospital of Bangladesh. MMJ. 2014;23(2):254-260.

11. Soltanoff W , Montclair NJ . A comparative study of the single visit and the multiplevisit endodontic precedure. J Endod. 1978;4:278-281.

12. Ether S. A comparison of one and two visit endodontics . J farmacia Odontol. 1978;8:215.

13. Ng YL, Glennon JP, Setchell DJ, Gulabivala K. Prevalence of and factors affectig post obturation pain in patients undergoing root canal treatment. Int Endod J. 2004;37:381-391.

14. Gesi A, Hakerberg M, Warfvinge J,Bergenholtz G. Incidence of periapical lesions and clinical symptoms after pulpectomy : A clinical and radiographic evaluation of 1 versus 2 session treatment . Oral Surg, Oral Med and Oral Pathol. 2006; 101(3):379-388.

15. Walton R, Fouad A. Endodontic inter appointment flare - ups: A prospective study of incidence and related factors. J Endod. 1992;18(4):172-177.

16. Dall AQ, Sheikh I, Khoso NA. Post obturation pain after single visit endodonties in teeth with pulpal necrosis. JPDA. 2010; 19: 148-154.

17. Alcam T, Tinaz AC. Inter appointment emergencies in teeth with necrotic pulps. J Endod. 2002; 28 (5): 375-377.

18. Imura N, Zuolo MI. Factors associated with endodontic flare ups: A prospective study. Int Endod J. 1995; 28: 261-265.

19. Ince B, Ercan E, Dalli M, Dulgergil CT, Zorba YO, Colak H. Incidence of postoperative pain after single- and multi visit endodontic treatment in teeth with vital and non vital pulp. Eur J Dent. 2009; 3: 273 -279.

20. Eleazer PD, Eleazer KR. Flare up rate in pulpally necrotic molars in one visit versus two visit endodontic treatment . J Endod. 1998;24: 614-616.

21. Fava LRG. A comparision of one varsus two appointment enodontic therapy in teeth with non vital pulps. Int Endod J. 1989; 22 (4): 179-183.

22. Clem WH. Post treatment endodontic pain. JADA. 1970; 81: 1166-1170. 